\title{
Studi Eksperimen Pengaruh Variasi Kecepatan Putaran Kompresor Pada Sistem Pengkondisian Udara Dengan Pre-Cooling
}

\author{
Fariz Ibrohim dan Ary Bachtiar Khrisna Putra \\ Jurusan Teknik Mesin, Fakultas Teknologi Industri, Institut Teknologi Sepuluh Nopember (ITS) \\ Jl. Arief Rahman Hakim, Surabaya 60111 Indonesia \\ e-mail: arybach@me.its.ac.id
}

\begin{abstract}
Abstrak - Indonesia adalah negara beriklim tropis dimana temperatur udaranya cukup tinggi sehingga penggunaan akan sistem pendingin dan pengkondisian udara (Air Condtioning) sangatlah di butuhkan. Eksperimen kali ini adalah memodifikasi sistem pengkondisian udara biasa menjadi sistem yang baru dengan 2 (dua) unit evapotaror dan 1 (satu) unit outdoor ditambah pre-cooling yang bertujuan untuk menaikkan performa dari sistem pengkondisian udara. Salah satu cara menaikkan perfroma sistem pengkondisian yang sudah dimodifikasi adalah dengan cara menvariasikan kecepatan putaran kompresor sehingga didapatkan performa yang maksimum. Oleh karena itu, dilakukan variasi pada sistem modifikasi yang sama dengan 5 (lima) kecepatan putaran kompresor yang berbeda, yaitu: $1800 \mathrm{rpm}, 2100 \mathrm{rpm}, 2400 \mathrm{rpm}$, 2700 rpm dan 3000 rpm. Ekpermen dilakukan pada masinmasing kecepatan fan evaporator dengan pengambilan data 20 kali pada 13 titik pengukuran untuk sekali variasi. Hasil yang didapat dari studi eksperimen pengaruh variasi kecepatan putaran kompresor pada sistem pengkondisian udara dengan precooling memiliki performa untuk kecepatan fan low COP sebesar 5,097 dan HRR sebesar 1,175, untuk kecepatan fan medium COP sebesar 5,103 dan HRR sebesar 1,176, dan untuk kecepatan fan low COP sebesar 5,201 dan HRR sebesar 1,175. Performa maksimum baik untuk kecepatan fan low, medium, dan high dari sistem yang telah dimodifikasi tersebut dicapai pada kecepatan putaran 3000 rpm dengan performa efisiensi kompresor adalah $73 \%$, COP thermal adalah 5,09, COP elektrik adalah 4,39, dan HRR adalah 1,17.
\end{abstract}

Kata Kunci- kecepatan putaran kompresor, modifikasi, performa, sistem pengkondisian udara.

\section{PENDAHULUAN}

$\mathrm{I}_{\mathrm{ten}}^{\mathrm{N}}$ NDONESIA adalah negara beriklim tropis dimana temperatur udaranya cukup tinggi sehingga penggunaan akan sistem pendingin dan pengkondisian udara (Air Condtioning) sangatlah di butuhkan baik di dunia industri, komersial, tranportasi, kesehatan, gedung-gedung perkantoran maupun rumah tangga. Pengkondisian udara adalah suatu mesin yang digunakan untuk mengkondisikan udara dengan cara menyerap kalor udara dalam ruangan kemudian kalor tersebut dilepaskan ke udara lingkungan menggunakan sistem rerigerasi kompresi uap. Pada sistem kompersi uap biasa hanya terdapat masing-masing satu unit kompresor, kondensor (air cooled condensor), alat ekspansi dan evaporator.
Pada sistem kompresi uap, pengeluaran kalor pada kondenser dapat mencapai empat kali dari masukan daya kompresi. Temperatur refrigeran keluar kompresor dapat mencapai $50^{\circ} \mathrm{C}$ tergantung pada kondisi udara ambien. Karena temperatur keluaran kompresor yang masing tinggi sehingga dapat ditambahkan suatu alat pre-cooling yang berguna untuk meningkatkan performa dari suatu sistem pengkondisian udara. Selain meningkatkan performa dari sistem pengkondisian udara, pre-cooling juga dapat memanfaatkan energi buang yang pada umumnya kalor dari kondenser dibuang langsung ke udara lingkungan.

Salah satu cara meningkatkan performa sistem pengkondian udara adalah dengan memvariasi kecepatan putaran kompresor. Oleh sebab itu salah satu cara untuk mendapatkan performansi yang maksimal adalah dengan melakukan variasi terhadap putaran kompresor, putaran kompresor ini akan mempengarui besarnya laju aliran massa yang dikompresikan sehingga menyebabkan perubahan kerja baik pada kondensor maupun evaporator yang berpengaruh terhadap performance dari sistem itu sendiri. Variasi putaran kompresor ini dapat dilakukan dengan cara menambahkan inverter sebagai pengubah frekuensi listrik yang masuk pada kompresor. Dengan variasi tersebut maka didapatkan putaran yang cocok untuk sistem yang telah dimodifikasi tersebut dengan cara mengetahui COP maksimum serta konsumsi daya kompresor minimum.

\section{URAIAN PENELITIAN}

\section{A. Sistem Refrigerasi}

Refrijerasi merupakan proses penyerapan kalor dari ruangan bertemperatur tinggi dan memindahkan kalor tersebut ke suatu medium tertentu tertentu yang bertemperatur lebih rendah sehingga didapatkan tercapainya suatu temperatur dan dipertahankannya termperatur tersebut di bawah temperatur lingkungan. Penyerapan dan pemindahan kalor ini menggunakan suatu medium yang disebut refrijeran.

Sistem refrijerasi adalah kombinasi kombinasi komponen, peralatan dan perpipaan, yang dihubungkan untuk menghasilkan efek pendinginan sehingga dapat menjadikan kondisi temperatur suatu ruangan berada di bawah temperatur semula. Pada prinsipnya dari sistem refrigerasi memanfaatkan 
prinsip dasar termodinmika dimana kalor bergerak dari temperatur tinggi ke temperatur rendah pada suatu media. Kondisi temperatur rendah yang dihasilkan oleh suatu sistem refrigerasi diakibatkan oleh penyerapan panas pada reservoir dingin yang merupakan salah satu bagian sistem refrigerasi tersebut. Panas yang diserap bersama-sama energi (kerja) yang diberikan kerja luar dibuang pada bagian sistem refrigerasi yang disebut reservoir panas.

\section{B. Modifikasi Sistem Refrigerasi Uap}

Sistem refrigerasi kompresi uap yang telah dimodifikasi adalah sistem yang memiliki komponen tambahan yaitu 1 unit evaporator dan 1 unit heat exchanger sebagai proses precooling.

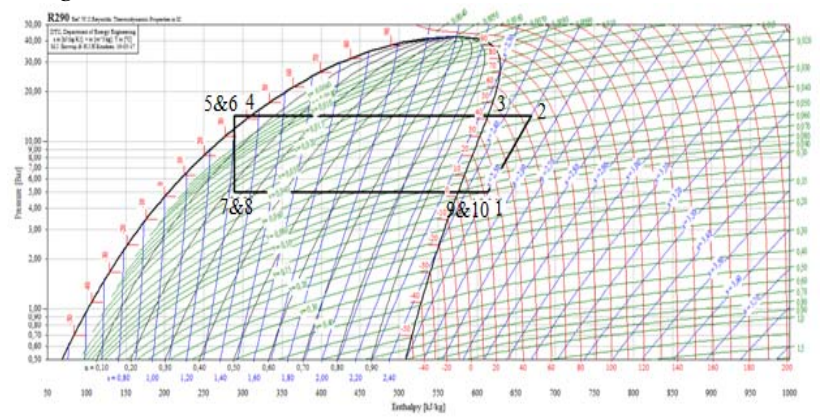

Gambar 1. P-h Diagram Sistem Refrigerasi Uap yang Telah Dimodifikasi

Gambar 1 adalah gambar sistem kompresi uap yang sudah dimodifikasi sehingga terdapat beberapa komponen tambahan pada sistem tersebut. Berikut ini adalah proses-proses yang membentuk siklus kompresi uap yang telah dimodifikasi :

- Proses 1-2: kompresi isentropi.

- Proses 2-3: pelepasan kalor secara isobaris pada precooling, menyebabkan penurunan panas lanjut (desuperheating).

- Proses 3-4: pelepasan kalor secara isobaris pada air cooled condensor, menyebabkan penurunan panas lanjut (desuperheating) dan proses pengembunan (kondensasi).

- Proses 5 \& 6: titik percabangan sebelum masuk pipa kapiler 1 dan pipa kapiler 2.

- Proses 5-7: proses penurunan tekanan dengan isoentalpi pada pipa kapiler 1.

- Proses 6-8: proses penurunan tekanan dengan isoentalpi pada pipa kapiler 2 .

- Proses 7-9: penambahan kalor pada tekanan tetap pada evaporator 1, yang menyebabkan penguapan menuju uap jenuh atau uap panas lanjut (superheated).

- Proses 8 -10: penambahan kalor pada tekanan tetap pada evaporator 2, yang menyebabkan penguapan menuju uap jenuh atau uap panas lanjut (superheated).

\section{Kompresor}

Kompresor adalah jantung dari sistem kompresi uap karena fungsinya untuk memompa refrigeran agar tetap bersirkulasi di dalam sistem selain itu kompresor berfungsi untuk mengkompresi refrigeran uap agar mempunyai tekanan yang tinggi untuk memasuki kondensor.

$$
\dot{W}_{c}=\dot{m}\left(h_{2}-h_{1}\right)
$$

\section{Kondensor}

Kondensor Berfungsi sebagai alat penukar kalor, menurunkan temperatur refrigeran, dan mengubah wujud refrigeran dari fasa gas menjadi fasa cair. Kondensor berfungsi sebagai pembuang panas (heat rejection) dari dalam sistem ke luar sistem.

a) Kapasitas pre-cooling

$$
\dot{Q}_{\text {pre-cooling }}=\dot{m}\left(h_{2}-h_{3}\right)
$$

b) Kapasitas air cooled condensor

$$
\dot{Q}_{\text {cond }}=\dot{m}\left(h_{3}-h_{4}\right)
$$

\section{Evaporator}

Komponen ini berfungsi untuk menyerap panas dari ruangan. Panas tersebut diserap dan dialirkan melalu heat exchanger kemudian dipindahkan ke refrigeran.

a) Kapasitas evaporator 1

$$
\dot{Q}_{e 1}=\frac{\dot{m}}{2}\left(h_{9}-h_{7}\right)
$$

b) Kapasitas evaporator 2

$$
\dot{Q}_{e 2}=\frac{\dot{m}}{2}\left(h_{10}-h_{8}\right)
$$

\section{Alat ekspansi}

Alat ekspansi menjadi komponen penentu dalam sistem pendinginan. Refrijeran pada fase cair dari kondensor yang akan diuapkan di evaporator dikontrol oleh alat ekspansi yang menyebabkan fasenya berubah menjadi campuran cair jenuh dan uap kemudian tekanannya pun juga ikut turun. Proses ideal ekspansi berlangsung secara isoentalpi. Besarnya perubahan entalpi pada proses ekspansi adalah :

$$
h_{5}=h_{7}
$$

\section{Koefisien Unjuk Kerja (COP) Thermal}

Koefisien unjuk kerja (COP) thermal adalah unjuk kerja teoritis yang didapatkan dari perbandingan kalor yang diserap oleh evaporator dengan dayang yang dibutuhkan kompresor :

$$
\mathrm{COP}_{\text {thermal }}=\frac{\dot{Q}_{e} \text { total }}{\dot{W}_{c}}=\frac{\frac{\dot{m}}{2}\left(h_{9}-h_{7}\right)+\frac{\dot{m}}{2}\left(h_{10}-h_{8}\right)}{\dot{m}\left(h_{2}-h_{1}\right)}
$$

\section{Heat Rejection Ratio (HRR)}

Laju perpindahan panas pada kondensor jika kaitannya dengan kapasitas refrigerasi dinyatakan sebagai Heat Rejection Ratio (HRR) dapat dinyatakan dengan membagi besarnya kalor yang dilepaskan kondensor dibagi dengan besarnya kalor yang diserap oleh refrigeran.

$$
H R R=\frac{\dot{Q}_{c} \text { total }}{\dot{Q}_{e} \text { total }}=\frac{\dot{m}\left(h_{2}-h_{3}\right)+\dot{m}\left(h_{3}-h_{4}\right)}{\frac{\dot{m}}{2}\left(h_{9}-h_{7}\right)+\frac{\dot{m}}{2}\left(h_{10}-h_{8}\right)}
$$

\section{E. Heat Exchanger}

Alat penukar kalor (Heat Exchanger) merupakan sebuah alat yang berfungsi untuk menurunkan atau meningkatkan 
meningkatkan temperatur sebuah sistem dengan memanfaatkan suatu media pendingin atau pemanas sehingga kalor dapat berpindah dari temperatur tinggi ke temperatur rendah. Pada eksperimen kali ini heat exchanger yang dugunakan adalah jenis concentric tube dengan jenis aliran conter flow [5].

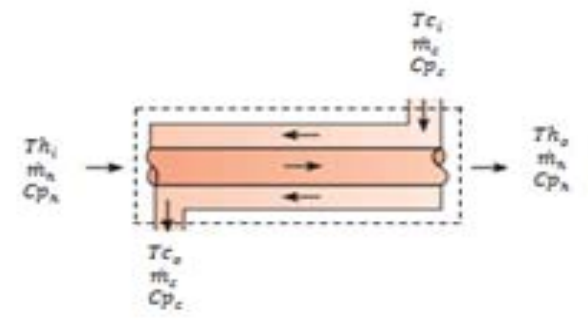

Gambar 2. Concentric Tube Heat Exchanger Dengan Aliran Counter Flow

Untuk mengetahui kinerja heat exchanger maka dapat digunakan effectiveness dari heat exchanger itu sendiri. Untuk mencari hal tersebut maka harus diketahui nilai perpindahan kalor aktual dan perpindahan kalo maksimum $\left(\mathrm{q}_{\max }\right)$ atau perpindahan kalor yang diharapkan dari heat exchanger.

$$
\varepsilon=\frac{C_{c}\left(T_{c, o}-T_{c, i}\right)}{C_{\min }\left(T_{h, i}-T_{c, i}\right)}
$$

Untuk mengevaluasi kinerja Number of Transfer Units (NTU) heat exchanger tipe concentric tube dengan aliran counter flow digunakan perumusan sevagai berikut :

$$
N T U=\frac{1}{C_{r}-1} \ln \left(\frac{\varepsilon-1}{\varepsilon C_{r}-1}\right) \text { untuk }\left(\mathrm{C}_{\mathrm{r}}<1\right)
$$

\section{F. Penelitian Terdahulu}

Pada tahun 2011 Ragil Heri Nurambyah melakukan penelitian dengan judul "Studi Eksperimental Perbandingan Refrijeran R-12 Dengan Hydrocarbon MC-12 Pada Sistem Pendingin Dengan Varasi Putaran Kompresor”

COP input $=f($ putaran kompresor $)$

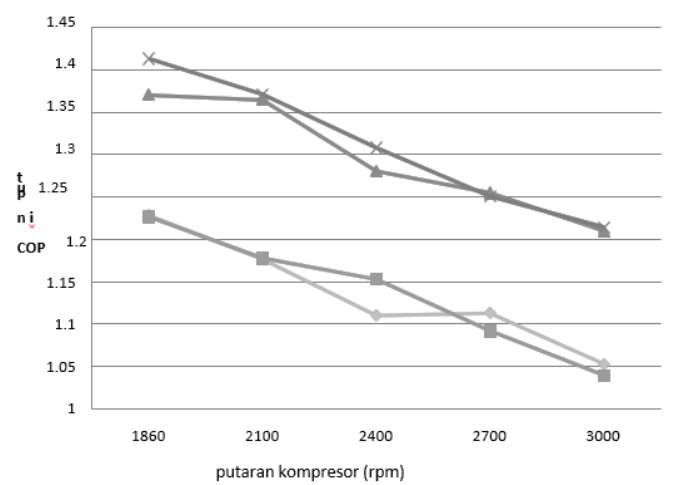

Gambar 3. Grafik hasil penelitian Ragil Heri Nurambyah (2011)

Gambar diatas menunjukkan hasil penelitian Ragil Heri Nurambyah yang melakukan penelitian dengan merubah kecepatan putan kompresor pada sistem pendingin ruangangan (air conditioner) dengan mengatur frekuensi listrik kompresor. Dalam penelitian ragil membandingkan 2 refrigeran sebagi fluida kerja pada sistem refrigerasi. Dari hasil penelitian dapat dilihan bahwa peninggkatan nilai COP berbanding terbalik dengan peninggkatan kecepatan putar. Dimana COP akan semakin besar seiring dengan menurunnya kecepatan putar motor kompresor. Sebaliknya, penambahan beban pada sistem meningkatkan nilai COP dari sistem refrigerasi.

\section{METODELOGI PENELITIAN}

\section{A. Skema Modifikasi Sistem Pengkondisian Udara}

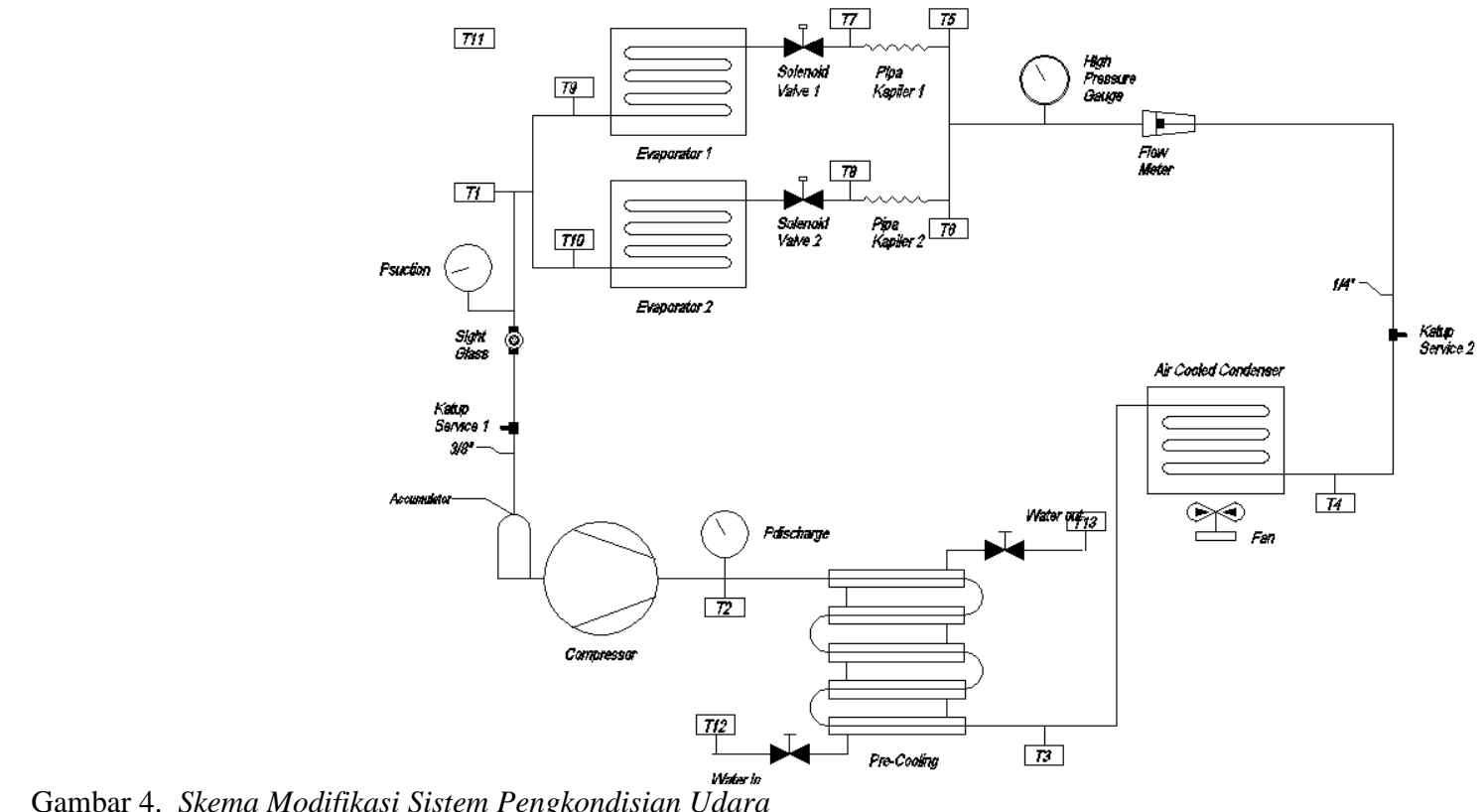

Gambar 4. Skema Modifikasi Sistem Pengkondisian Udara 
Gambar 4 adalah sistem pengkondisian udara yang telah dimodifikasi yang terdapat beberapa komponen yaitu : kompresor, pre-cooling, air cooled condensor, 2 pipa kapiler dan 2 evaporator.

\section{B. Alat Ukur}

Berikut ini adalah alat ukur yang digunakan pada eksperimen kali ini :

1. Thermocouple tipe $\mathrm{K}: 13$ titik pengukuran temperatur.

2. Pressure Gauge : 2 high pressure dan 1 low pressure.

3. Flow meter

4. Amperemeter

5. Data akuisisi

\section{Prinsip Pengujian}

Pengujian pada sistem pengkondisian udara yang telah dimodifikasi pada kali ini menggunakan refrijeran Musicool22 dengan tekanan suction kompresor sesuai rekomendasi dari PT. Pertamina yaitu 60Psig - 80 Psig [2]. Variasi kecepatan putaran kompresor yang dilakukan adalah 1800 rpm. 2100 rpm, 2400 rpm dan 3000 rpm. Pengambilan data dilakukan setelah sistem sudah dalam kondisi steady state. Data yang diolah data rata-rata dari pengukuran pada saat sistem telah steady, ada 5 data yang diambil setiap 5 menit.

\section{HASIL DAN ANALISA}

A.Grafik COP Thermal Fungsi Kecepatan Putaran Kompresor

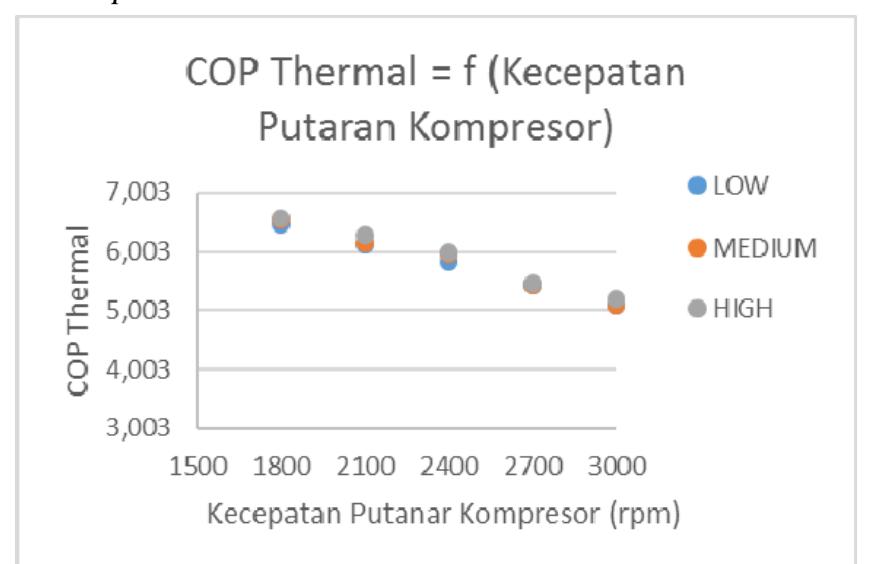

Gambar 5. Grafik COP thermal fungsi kecepatan putaran kompresor

Gambar diatas menunjukkan COP thermal. Grafik tersebut menunjukkan tren grafik yang menurun. Dari gambar grafik terlihat bahwa tidak ada perbedaan antara COP thermal untuk kecepatan blower evaporator low, medium dan high. Dari gambar grafik juga terlihat COP thermal pada kecepatan putaran kompresor yang lebih tinggi memiliki nilai yang lebih kecil. COP thermal terendah yaitu 5,1 pada kecepatan putaran kompresor $3000 \mathrm{rpm}$ sedangkan COP thermal tertinggi yaitu 6,54 pada kecepatan putaran kompresor 1800 rpm.

Penurunan COP thermal dari kecepatan putaran kompresor rendah hingga putaran maksimum disebabkan semakin tinggi kecepatan putaran kompresor. Penurunan tersebut diakibatkan kenaikan total kapasitas evaporator tidak sebanding dengan kerja kompresor sesuai dengan persamaan 2.17.

B. Grafik HRR Fungsi Kecepatan Putaran Kompresor

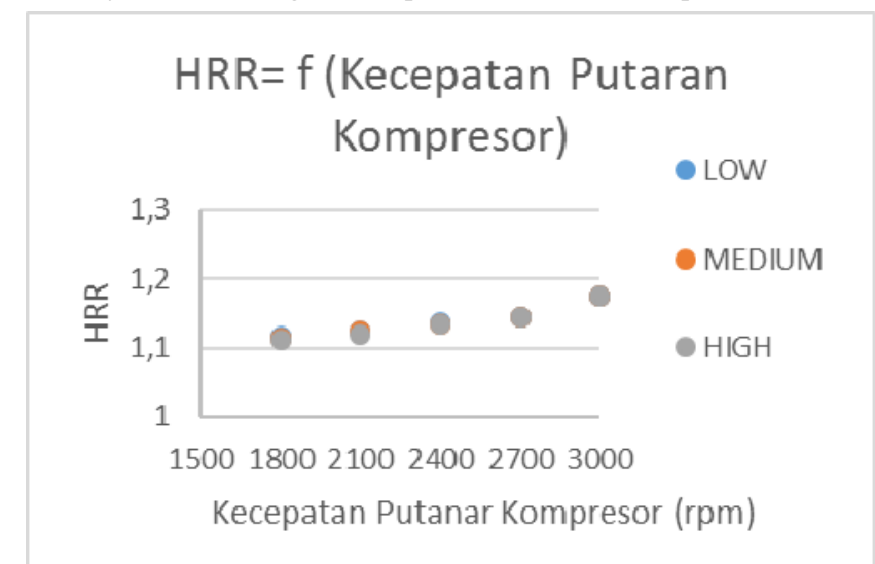

Gambar 6. Grafik HRR fungsi kecepatan putaran kompresor

Gambar diatas menunjukkan HRR. Grafik tersebut menunjukkan tren grafik yang naik. Dari gambar grafik terlihat bahwa tidak ada perbedaan antara HRR untuk kecepatan blower evaporator low, medium dan high. Dari gambar grafik juga HRR pada kecepatan putaran kompresor yang lebih tinggi memiliki nilai yang lebih tinggi. HRR dari kompresor terendah yaitu 1,11 pada kecepatan putaran kompresor $1800 \mathrm{rpm}$ sedangkan tekanan refrigeran yang keluar dari kompresor tertinggi yaitu 1,175 pada kecepatan putaran kompresor 3000 rpm.

Naiknya HRR dari kecepatan putaran kompresor rendah hingga putaran maksimum disebabkan semakin tinggi kecepatan putaran. Kenaikan tersebut sesuai karena kenaikan total kapasitas kondensor lebih tinggi dibandingkan kenaikan total kapasitas evaporator.

\section{Grafik Effectivenes Heat Exchanger Fungsi Kecepatan Putaran Kompresor}

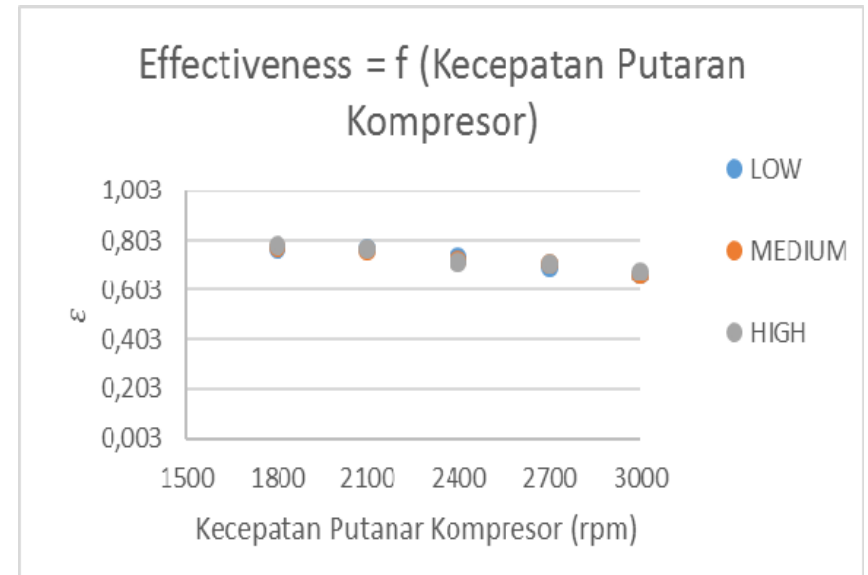

Gambar 7. Grafik effectivenes heat exchanger fungsi kecepatan putaran kompresor

Gambar diatas menunjukkan effectivenes heat exchanger. Grafik tersebut menunjukkan tren grafik yang menurun. Dari gambar grafik juga terlihat effectivenes heat exchanger pada kecepatan putaran kompresor rendah memiliki nilai effectivenes heat exchanger yang lebih yang 
tinggi, semakin bertambah cepatnya kecepatan putaran kompresor maka nilai effectivenes heat exchanger semakin menurun. Effectivenes heat exchanger terendah yaitu 0,6673 pada kecepatan putaran kompresor 3000 rpm sedangkan effectivenes heat exchanger tertinggi yaitu 0,7739 pada kecepatan putaran kompresor 1800 rpm (low).

D.Grafik NTU Heat Exchanger Fungsi Kecepatan Putaran Kompresor

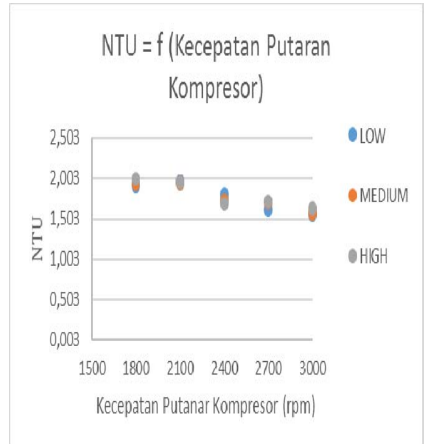

Gambar 8. Grafik NTU heat exchanger fungsi kecepatan putaran kompresor

Gambar diatas menunjukkan NTU heat exchanger. Grafik tersebut menunjukkan tren yang naik. Dari gambar grafik juga terlihat NTU heat exchanger dari kompresor pada kecepatan putaran kompresor yang rendah memiliki NTU heat exchanger yang tinggi, seiring bertambah cepatnya kecepatan putaran kompresor maka nilai NTU heat exchanger semakin turun. NTU heat exchanger terendah yaitu 1,575 pada kecepatan putaran kompresor 1800 rpm sedangkan tekanan refrigeran yang keluar dari kompresor tertinggi yaitu 1,947 pada kecepatan putaran kompresor 3000 rpm (medium).

\section{E.P-h Diagram Sistem Pengkondisian Udara dengan Variasi Kecepatan Putaran Kompresor}

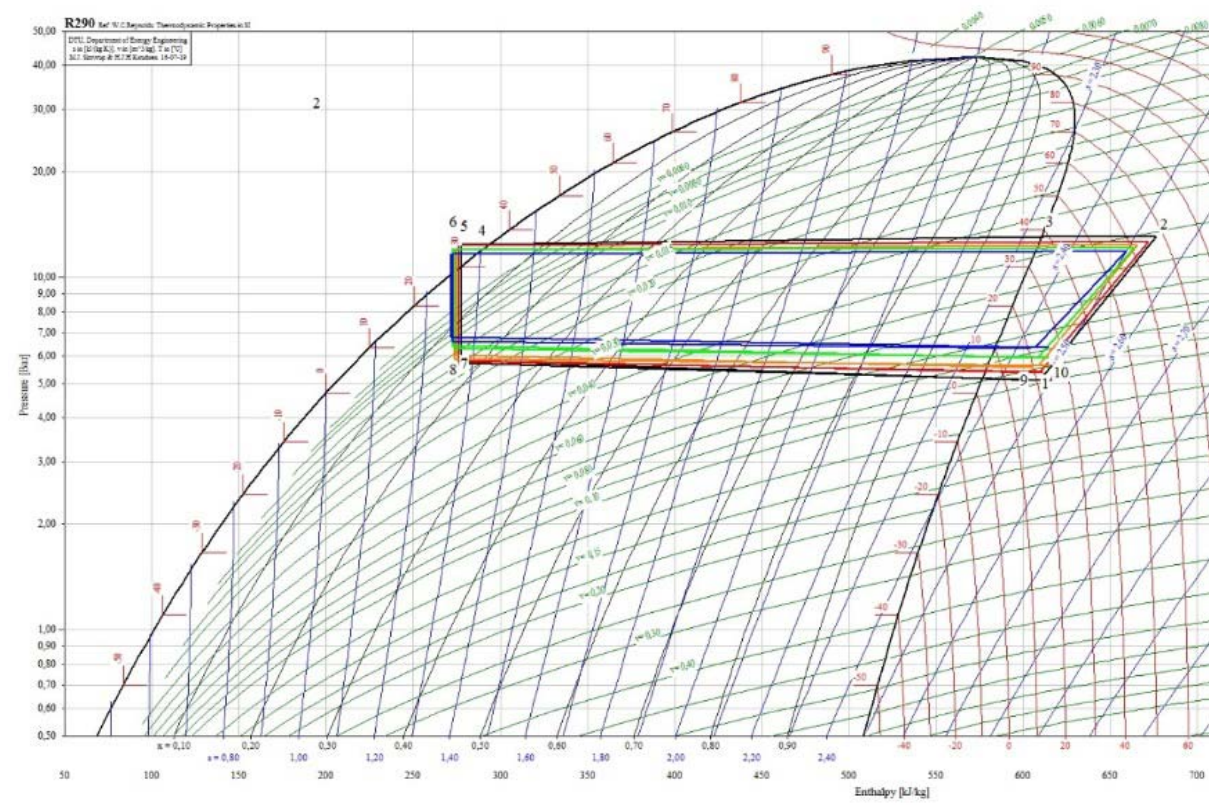

Gambar 7. p-h diagram kecepatan fan evaporator low

Pada gambar 6 p-h diagram kecepatan blower evaporator low dibawah membandingkan perbedaan antara sistem dengan variasi kecepatan putaran kompresor $1800 \mathrm{rpm}, 2100 \mathrm{rpm}$, $2400 \mathrm{rpm}, 2700 \mathrm{rpm}$ dan $3000 \mathrm{rpm}$. Garis warna biru menunjukkan kurva sistem dengan kecepatan putaran kompresor 1800 rpm, garis warna hijau menunjukkan kurva sistem dengan kecepatan putaran kompresor 2100 rpm, garis warna orange menunjukkan kurva sistem dengan kecepatan putaran kompresor 2400 rpm, garis warna merah menunjukkan kurva sistem dengan kecepatan putaran kompresor $2700 \mathrm{rpm}$ dan garis warna hitam menunjukkan kurva sistem dengan kecepatan putaran kompresor 3000 rpm.
Pada gambar plot terlihat semakin bertambah cepat kecepatan putaran kompresor maka proses kompresi semakin panjang yang berarti pressure ratio semakin tinggi dan refrigeran keluaran kompresor semakin superheated serta proses ekspansi semakin panjang pula sehingga tekanan dan temperatur pada masuk evaporator semakin rendah. Bertambah cepat kecepatan kompresor juga akan mengakibatkan laju aliran massa refrigeran semakin meningkat yang berakibat kapasitas evaporasi, kapasitas kondensasi semakin meningkat. 


\section{KESIMPULAN}

Kesimpulan dari hasil studi eksperimen pengaruh variasi kecepatan putaran kompresor pada sistem refrigerasi yang telah dimodifikasi adalah sebagai berikut:

1. Performa sistem refrigerasi yang telah dimodifikasi adalah COP untuk kecepatan blower low bernilai 5,097, COP untuk kecepatan blower medium bernilai 5,103 dan COP untuk kecepatan blower low bernilai 5,201. Sedangakn HRR untuk kecepatan blower low bernilai 1,175, HRR untuk kecepatan blower low bernilai 1,176 dan HRR untuk kecepatan blower low bernilai 1,175

2. Performa maksimum darihasil studi eksperimen pengaruh variasi kecepatan putaran kompresor pada sistem refrigerasi yang telah dimodifikasi dengan kecepatarn putaran kompresor 1800 rpm, 2100 rpm, 2400 rpm, 2700 rpm, dan 3000 rpm didapat pada kecepatan putaran 3000 rpm baik untuk kecepatan blower low, medium dan high.

- COP thermal adalah 5,09

- COP elektrik adalah 4,39

- HRR adalah 1,17

- Effectiveness adalah 0,66, dan

- NTU adalah 1,56

\section{UCAPAN TERIMA KASIH}

Tuliskan ucapan terima kasih dengan bahasa baku, misalnya, "Penulis F.I. (inisial nama mahasiswa) mengucapkan terima kasih kepada Pak Ary Bachtiar, ST., MT., PhD. yang telah membimbing, Kedua Orang Tua, Kakak, dan Adik yang telah memberikan dukungan finansial, dukungan doa, dan semangat, Muslikha yang telah memberikan semangat kepada penulis, Pak Minto dan Mas Erdin yang telah membantu penulis dalam menyelesaikan alat, serta Awan dan Arnovia yang telah bersama-sama berjuang menyelesaikan Tugas Akhir dengan alat yang sama.

\section{DAFTAR PUSTAKA}

[1] Bergman, Theodore L, dkk. "Fundamental of Heat and Mass Transfer", $7^{\text {th }}$ ed. John Wiley \& Son's, Inc. US.

[2] Moran, Michael J, dkk. "Fundamental of Engneering Thermodynamics", $7^{\text {th }}$ ed. John Wiley \& Son's, Inc. US.

[3] Nurambyah, Ragil Heri. "Studi Eksperimental Perbandingan Refrigeran R-12 dengan Hydrocarbon MC-12 pada Sistem Pendngin dengan Variasi Putaran Kompresor”. ITS. Surabaya. 2011. 